\title{
Comparison of Meteorological Measurements from Sparse and Dense Surface Observation Networks in the U.S. Southern Great Plains
}

February 2008

\section{J.W. Monroe}

Climate Research Section, Environmental Science Division/Argonne National Laboratory Cooperative Institute for Mesoscale Meteorological Studies/University of Oklahoma

\section{M.T. Ritsche, M. Franklin}

Climate Research Section, Environmental Science Division/Argonne National Laboratory,

\section{K.E. Kehoe}

Cooperative Institute for Mesoscale Meteorological Studies/University of Oklahoma

Work supported by the U.S. Department of Energy, Office of Science, Office of Biological and Environmental Research 


\section{DISCLAIMER}

This report was prepared as an account of work sponsored by the U.S. Government. Neither the United States nor any agency thereof, nor any of their employees, makes any warranty, express or implied, or assumes any legal liability or responsibility for the accuracy, completeness, or usefulness of any information, apparatus, product, or process disclosed, or represents that its use would not infringe privately owned rights. Reference herein to any specific commercial product, process, or service by trade name, trademark, manufacturer, or otherwise, does not necessarily constitute or imply its endorsement, recommendation, or favoring by the U.S. Government or any agency thereof. The views and opinions of authors expressed herein do not necessarily state or reflect those of the U.S. Government or any agency thereof. 


\section{Contents}

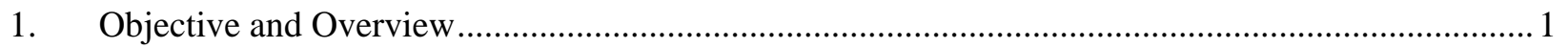

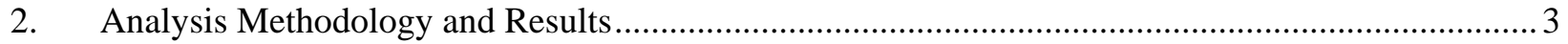

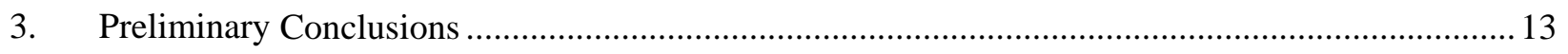

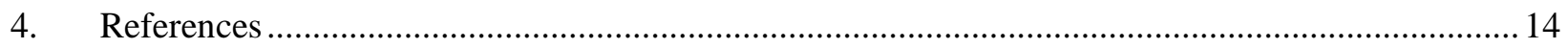

\section{Figures}

1. Locations of ARM SMOS stations and OKM stations addressed in this study............................... 1

2. Locations of stations and domains addressed in this study......................................................... 2

3. Scatter plots of observed relative humidity values in 1999-2006 at ARM SMOS station E1 versus central comparison station E4 in the sparse KS domain for (a) the standard DQO range test and (b) the tighter DQO range test.

4. Scatter plots for temperature and relative humidity, for (a) the relatively short inter-station distance of $16.34 \mathrm{~km}$ and (b) the relatively long inter-station distance of $423.61 \mathrm{~km}$.

5. Scatter plots for temperature and relative humidity for (a) an ARM-OKM station pair in the dense northern OK domain, distance $177.73 \mathrm{~km}$, and (b) an ARM-ARM station pair in the dense central OK domain, distance $162.99 \mathrm{~km}$.

6. Scatter plot for the temperature comparison between the BURN OKM station and the E27 ARM SMOS station

7. Scatter plots of $\rho$ for temperature versus distance for (a) ARM SMOS stations in the sparse KS domain and (b) OKM and ARM SMOS stations in the dense central OK domain.

8. Scatter plots of $\rho$ for relative humidity versus distance for (a) ARM SMOS stations in the sparse KS domain and (b) OKM and ARM SMOS stations in the dense central OK domain

9. Scatter plots of RMSD for temperatures versus distance for (a) ARM SMOS stations in the sparse KS domain and (b) OKM and ARM SMOS stations in the dense central OK domain.

10. Scatter plots of RMSD for relative humidity versus distance for (a) ARM SMOS stations in the sparse KS domain and (b) OKM and ARM SMOS stations in the dense central OK domain......

\section{Tables}

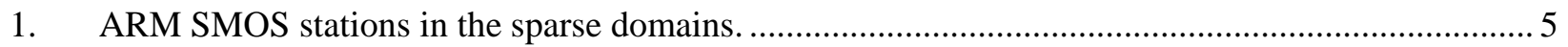

2. Distances between station pairs in the dense OK domains. ............................................................ 5

3. Calculated slopes and intercepts of LS fit lines from distance analysis of $\rho$ in each domain........... 13

4. Calculated slopes and intercepts of LS fit lines from distance analysis of RMSD in each domain 


\section{Objective and Overview}

The primary objective of this study was to analyze the spatial variability of temperature and relative humidity across Kansas (KS) and Oklahoma (OK) for sparse and dense networks by comparing data from (1) the Surface Meteorological Observing System (SMOS) installations at the Atmospheric Radiation Measurement (ARM; Peppler et al. 2008) Program’s Southern Great Plains site and (2) the Oklahoma Mesonet (OKM; McPherson et al. 2007). Given the wealth of observations available from these networks, this study provided the unique opportunity to determine, within a quantifiable statistical limit, an optimal distance between stations deployed for observation of the climatological values of temperature and relative humidity. Average distances between a given station and its closest neighboring station for the ARM SMOS ( $70 \mathrm{~km}$ ) and the OKM ( $30 \mathrm{~km}$; Brotzge and Richardson 2003) networks provided an excellent framework for comparisons of sparse and dense observations (Figure 1). This study further lays groundwork for a future investigation to determine the necessary spacing between observations for initialization of gridded numerical models.

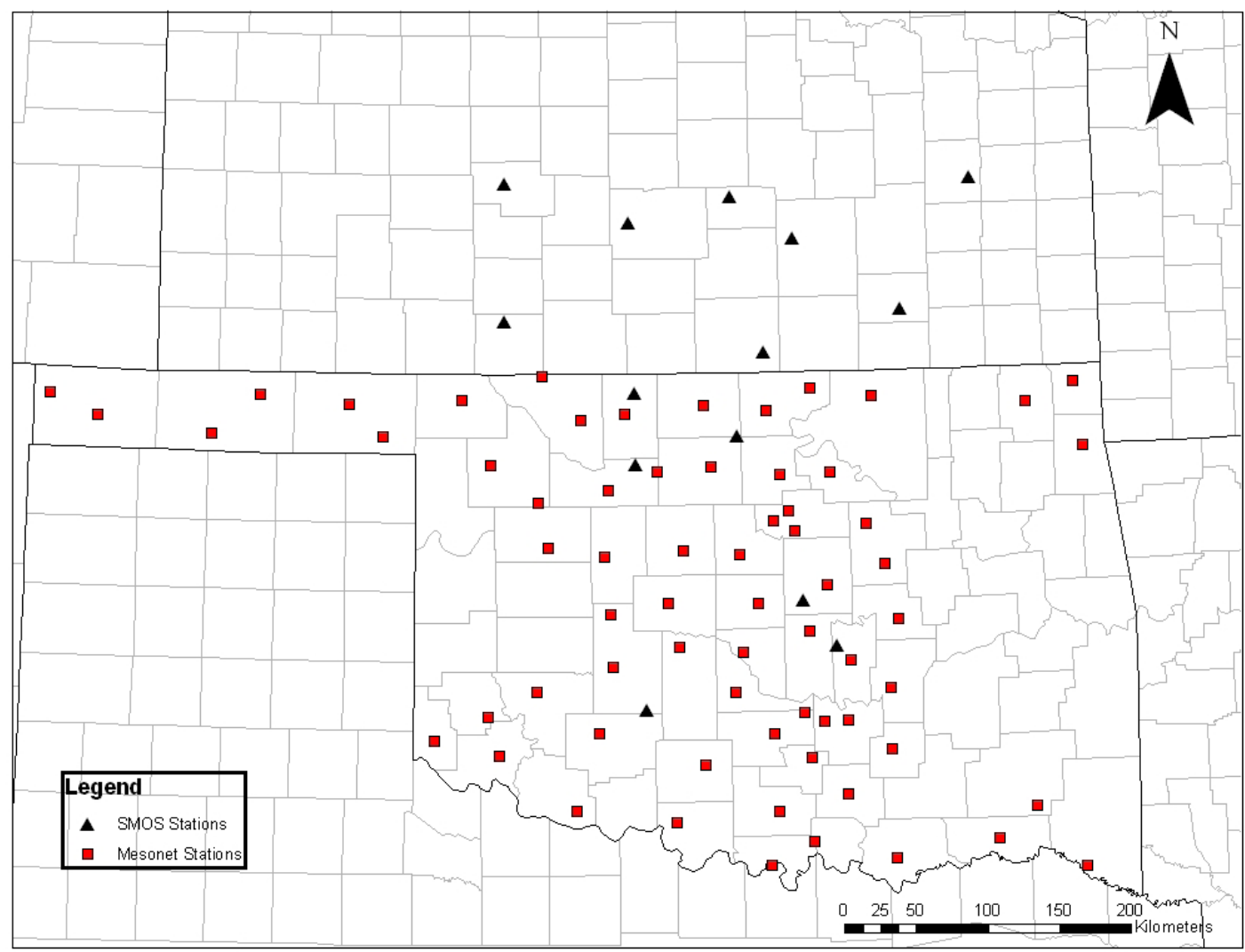

Figure 1: Locations of ARM SMOS stations and OKM stations addressed in this study.

The spatial variability of temperature and relative humidity was examined over KS and OK by comparing observations between station pairs located in three primary domains: (1) a sparse domain in KS, consisting only of ARM SMOS stations; (2) a dense domain centered in northern OK, consisting of both ARM SMOS and OKM stations; and (3) a dense domain centered in central OK, also consisting of both ARM SMOS and OKM stations (Figure 2). In addition, the ARM SMOS stations in OK were utilized to create two secondary sparse domains. 


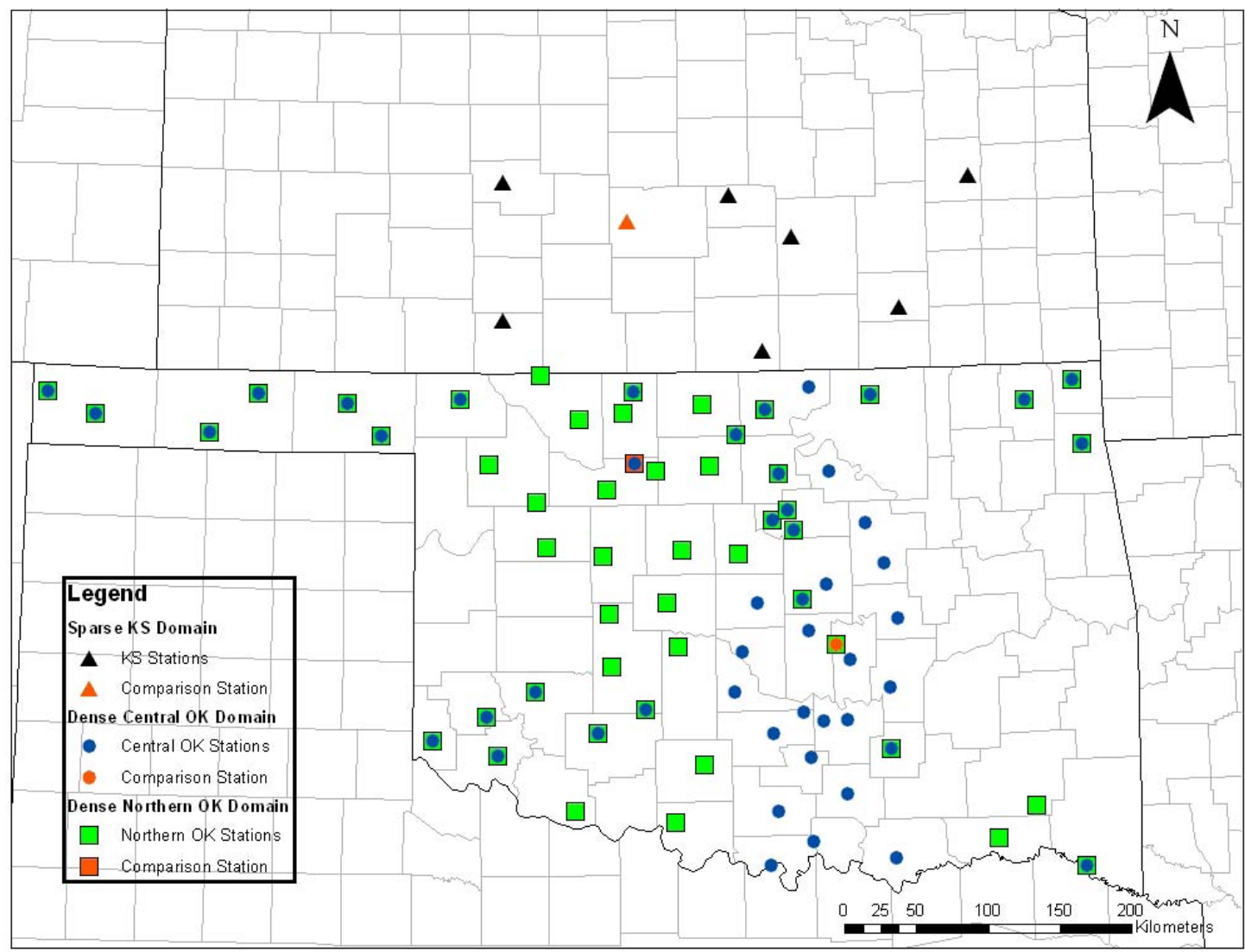

Figure 2: Locations of stations and domains addressed in this study.

Before the observations were compared, quality control (QC) beyond the standard ARM range test was added through implementation of tighter range tests specified by data quality objectives (DQOs). Furthermore, instances of poor-quality data were removed from the data set on the basis of ARM data quality reports (DQRs). Finally, to account for spatial differences in terrain, temperature observations were corrected to mean sea level by using a standard lapse rate of $6.5^{\circ} \mathrm{C} \mathrm{km}-1$ and the elevation of each observing station.

For the comparison, a central station was chosen in each domain. Observations during the time period 2004-2006 from each of the other stations within a respective domain were compared to those from this central station. The Pearson correlation coefficient ( $\rho$ ) and root-mean-square difference (RMSD) were the statistics used to quantify the relationship between station pairs. For each domain, the $\rho$ and RMSD values were plotted against the distance separating each station pair, and a least-squares (LS) regression line was fitted to the values. The regression slopes and intercepts were compared between the various domains.

The results of this analysis demonstrated positive correlations between all individual station pairs for both temperature and relative humidity. In addition, the $\rho$ and RMSD values for both temperature and relative humidity exhibited, in general, a linear relationship with distance from a central station. The calculated slope and intercept values were comparable across most domains, and spatial differences in temperature were smaller than those for relative humidity. 
The findings suggest that although the sparse networks studied might provide an accurate spatial representation for climatological values of temperature and relative humidity over the specific distances between stations, the relative importance of the temperature and relative humidity observations is a critical consideration in network design.

\section{Analysis Methodology and Results}

The data analyzed included 30-min-averaged temperature and relative humidity observations from both the ARM SMOS and OKM data archives. The original OKM archives consisted of data at 5-min intervals; these were averaged over 30-min intervals for direct comparison to the ARM SMOS observations. To ensure that only high-quality data were used, additional QC measures were implemented for the ARM SMOS observations. These included removal of observation times flagged in the ARM DQRs, as well as implementation of a tighter DQO range test for the relative humidity observations. The original DQO lower limit (-2\%) had been selected on the basis of the sensor's error and measurable range. Applying a more stringent lower limit of $0.1 \%$ removed many questionable observations (Figure 3). Because the OKM had its own QC system in place, the tighter DQO range tests and DQRs were not applied to the OKM observations.

(a)

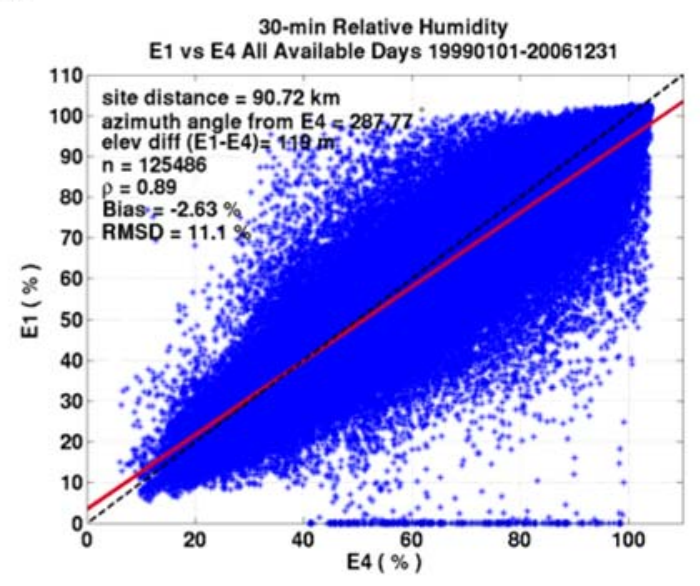

(b)

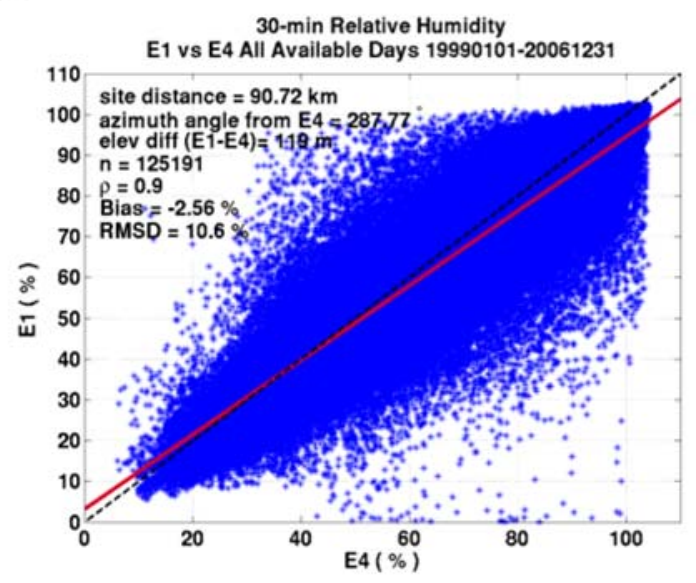

Figure 3: Scatter plots of observed relative humidity values in 1999-2006 at ARM SMOS station E1 versus central comparison station E4 in the sparse KS domain for (a) the standard DQO range test and (b) the tighter DQO range test.

Although the data archives for both the ARM SMOS and the OKM observations dated back to the mid 1990s, the processing time necessary to create the data sets led us to limit the study period to three years. To focus on the most recent data and work with complete calendar years, observations from 2004-2006 were selected. The OK climate during this period included a relatively cool, wet summer in 2004 and a prolonged drought with above-normal temperatures during much of 2005-2006. This drought ranked as one of the most severe on record in Oklahoma (McManus et al. 2004, 2006). Climate records for KS were not available to permit comparison of the KS observations during 2004-2006 with long-term mean values.

The sparse and dense domains were selected through a subjective process that included visual inspection of maps showing station locations across KS and OK. (Note that all ARM SMOS station identifiers 
consist of an "E" followed by a numeric value, while each OKM station identifier consists of a fourcharacter abbreviation of the town name nearest the station.) Because the average distance between a given station and its closest neighboring station was much greater for ARM SMOS $(\sim 70 \mathrm{~km})$ than OKM ( $30 \mathrm{~km})$, the sparse domains were created with only ARM SMOS stations. Also of interest was determination of how these stations would perform in the absence of a denser network such as the OKM.

The primary sparse domain (labeled "sparse KS domain”) was limited to ARM SMOS stations in KS in order to achieve independence of the OKM, which only contained stations in OK. Initially, five of the eight ARM SMOS stations in KS were selected for the sparse KS domain, and centrally located station E4 was chosen as the central comparison station. Subsequently, the three ARM SMOS stations in eastern KS were added to the sparse KS domain. As a result, the E4 extended facility was located slightly west of center in the domain as it was ultimately constituted (Figure 2).

The two primary dense domains consisted of both ARM SMOS and OKM stations in OK. One dense domain consisted of stations in the northern part of the state (labeled "dense northern OK domain”), while the other consisted of more centrally located stations (labeled "dense central OK domain"). For consistency with the sparse KS domain, an ARM SMOS station was selected as the central comparison station in each of the dense OK domains. For the dense northern OK domain, the E15 ARM SMOS extended facility was chosen; for the dense central OK domain, the E27 ARM SMOS extended facility located $\sim 130 \mathrm{~km}$ to the southeast was chosen.

To begin the subjective station selection process for each dense OK domain, most of the stations within a distance of $\sim 100 \mathrm{~km}$ from the central comparison station were initially included. Next, many of the distant OKM stations were added, along with stations at intermediate distances to fill gaps. Finally, the remaining ARM SMOS stations in OK were added to each of the dense OK domains, except for the E21 extended facility, which had a non-standard installation of temperature and relative humidity sensors above the tree canopy. The five ARM SMOS station pairs in each dense OK domain, when viewed independently from the OKM stations, were used as the secondary sparse domains for comparison with the primary sparse KS domain (Table 1).

Overall, each dense OK domain contained 6 ARM SMOS stations and 45 OKM stations, for a total of 50 station pairs per domain when compared to the central comparison station. The spatial extent of these dense OK domains was much greater than for the sparse KS domain, with maximum distances between stations in OK exceeding $500 \mathrm{~km}$. The dense OK domains also contained a much greater number of comparison station pairs with distances less than the maximum for the sparse KS domain, as well as a number of comparison station pairs with smaller distances not represented in KS (Table 2).

Once the study domains were selected, scatter plots of temperature and relative humidity were created for each station pair. To correct for the effects of terrain, the temperature values were corrected to mean sea level by using each station's elevation and a standard lapse rate of $6.5^{\circ} \mathrm{C} \mathrm{km-1}$. Next, $\rho$, mean difference (bias), and RMSD were computed.

As expected, the scatter plots for station pairs with greater distances exhibited larger spreads than plots for stations located closer together (Figure 4). For example, the RMSD for temperature of a dense northern OK station pair (E15-LAHO) $16.34 \mathrm{~km}$ apart was $1.05^{\circ} \mathrm{C}$, while the RMSD for a dense northern OK station pair (E15-IDAB) separated by $423.61 \mathrm{~km}$ was $4.67^{\circ} \mathrm{C}$. The differences in the RMSD for relative humidity between these two station pairs were even more dramatic $(6.45 \%$ and $18.9 \%$, 
respectively). For all station pairs examined, temperature and relative humidity observations were positively correlated $(\rho>0)$. In general, at equal distances, values of $\rho$ for temperature were greater than those for relative humidity. Similarly, RMSD values were smaller for temperature than for relative humidity. These patterns were seen for both ARM-ARM and ARM-OKM comparisons (Figure 5).

Table 1: ARM SMOS stations in the sparse domains.

\begin{tabular}{ccc}
\hline Comparison Station & \multicolumn{1}{c}{ Station Name } & $\begin{array}{c}\text { Distance from } \\
\text { Comparison Station (km) }\end{array}$ \\
\hline Sparse KS domain (primary sparse domain, 7 station pairs) & \\
E4: Plevna, KS & E5: Halstead, KS & 73.68 \\
& E1: Larned, KS & 90.72 \\
& E8: Coldwater, KS & 110.44 \\
& E6: Towanda, KS & 115.52 \\
& E9: Ashton, KS & 130.76 \\
& E7: Elk Falls, KS & 199.49 \\
& E3: LeRoy, KS & 240.72 \\
Sparse northern OK domain (secondary sparse domain, 5 station pairs) \\
E15: Ringwood, OK & E11: Byron, OK & 50.04 \\
& E13: Lamont, OK & 73.98 \\
& E20: Meeker, OK & 129.59 \\
& E27: Earlsboro, OK & 132.88 \\
& E24: Cyril, OK & 172.28 \\
Sparse central OK domain (secondary sparse domain, 5 station pairs) \\
E27: Earlsboro, OK & E20: Meeker, OK & 39.76 \\
& E24: Cyril, OK & 140.06 \\
& E13: Lamont, OK & 162.99 \\
& E15: Ringwood, OK & 189.89 \\
& E11: Byron, OK & 226.73 \\
\hline
\end{tabular}

Table 2: Distances between station pairs in the dense OK domains.

\begin{tabular}{lcccc}
\hline & \multicolumn{4}{c}{$\begin{array}{c}\text { Number of Stations within Indicated Distance of } \\
\text { Comparison Station (50 total pairs in each domain) }\end{array}$} \\
\cline { 2 - 5 } Comparison Station & $<50 \mathrm{~km}$ & $<100 \mathrm{~km}$ & $<150 \mathrm{~km}$ & $<250 \mathrm{~km}$ \\
\hline E15: Ringwood, OK (northern OK domain) & 4 & 15 & 25 & 38 \\
E27: Earlsboro, OK (central OK domain) & 6 & 19 & 26 & 42 \\
\hline
\end{tabular}


(a)

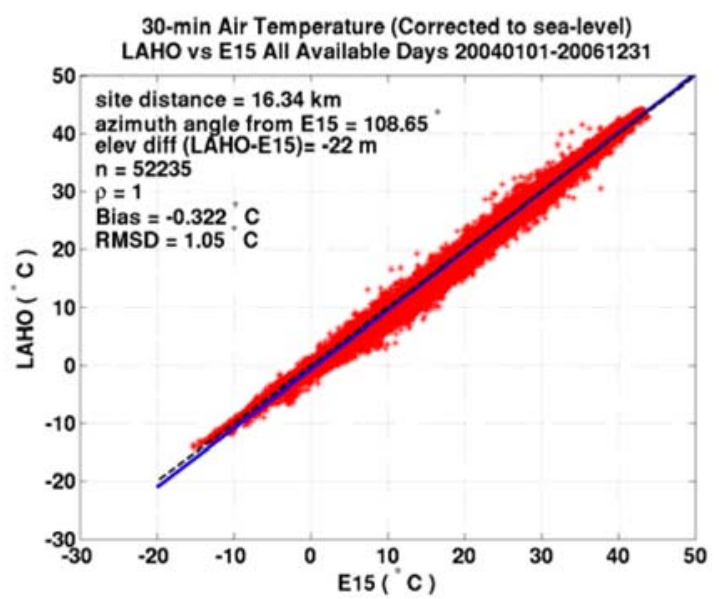

(b)

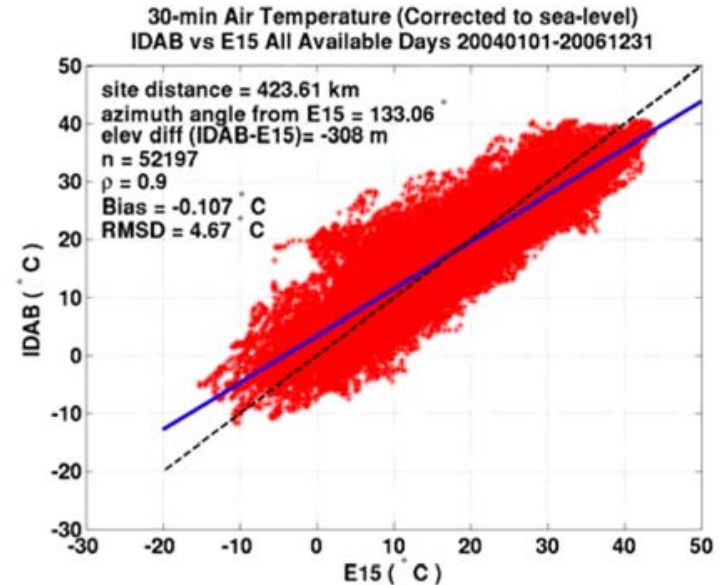

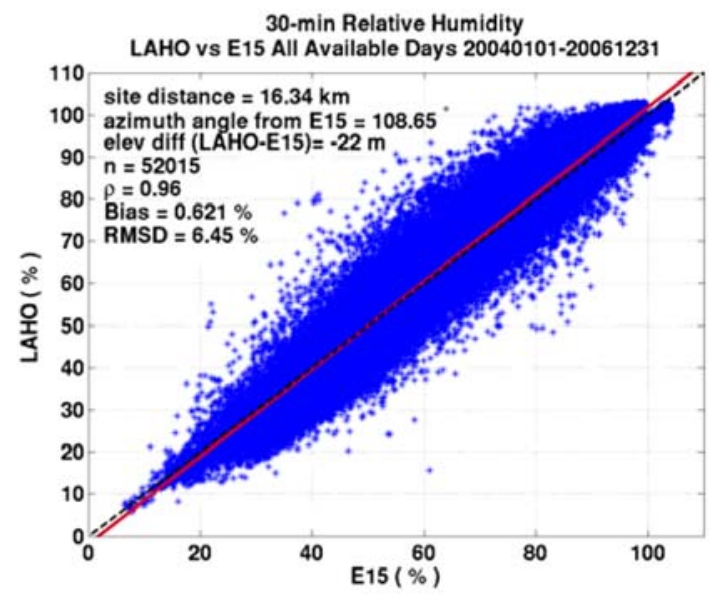

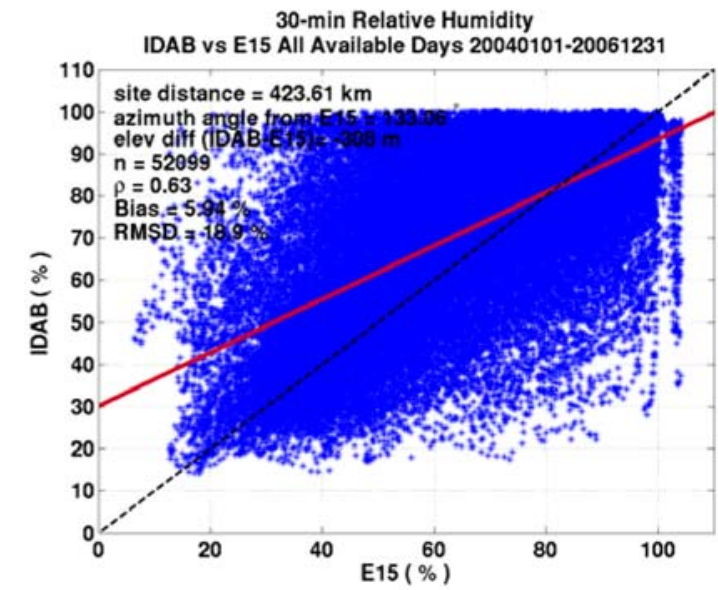

Figure 4: Scatter plots for temperature (left) and relative humidity (right), for (a) the relatively short interstation distance of $16.34 \mathrm{~km}$ and (b) the relatively long inter-station distance of $423.61 \mathrm{~km}$. 
(a)
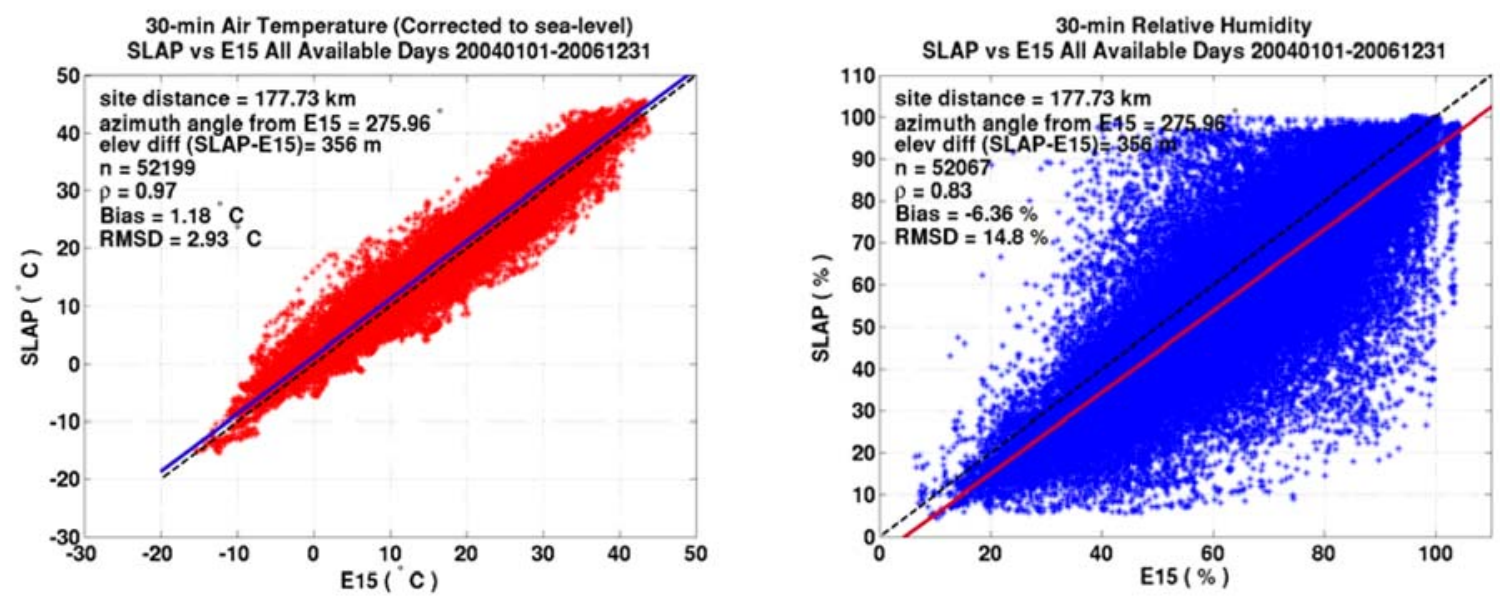

(b)
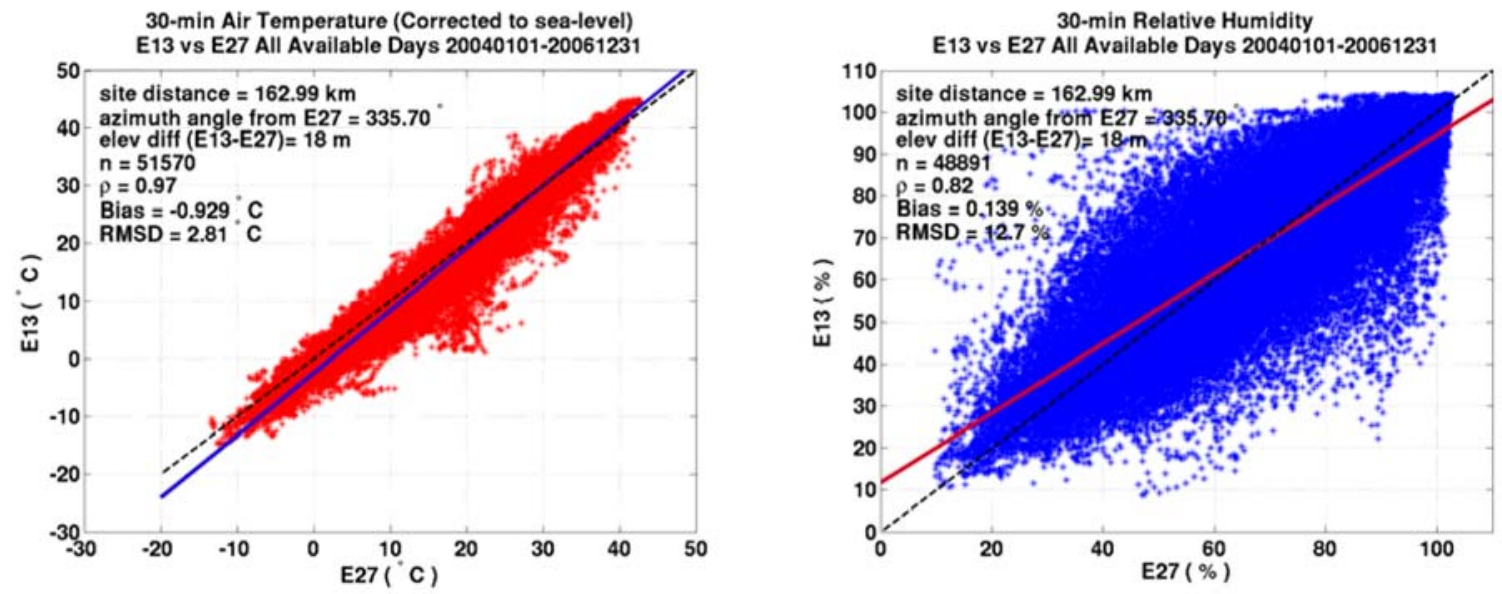

Figure 5: Scatter plots for temperature (left) and relative humidity (right) for (a) an ARM-OKM station pair in the dense northern OK domain, distance $177.73 \mathrm{~km}$, and (b) an ARM-ARM station pair in the dense central OK domain, distance $162.99 \mathrm{~km}$.

Despite the additional QC procedures applied to the analysis data sets, questionable distributions of data points were evident in the observations used for some station comparisons as finger-like projections in the scatter plots (Figure 6). Because 30-min-averaged observations were used here, these patterns could reflect the influence of mesoscale or microscale weather phenomena at one or more stations. A future investigation of the time series data will be required to determine the cause of these anomalies. Overall, only a very small percentage of observations was questionable. 


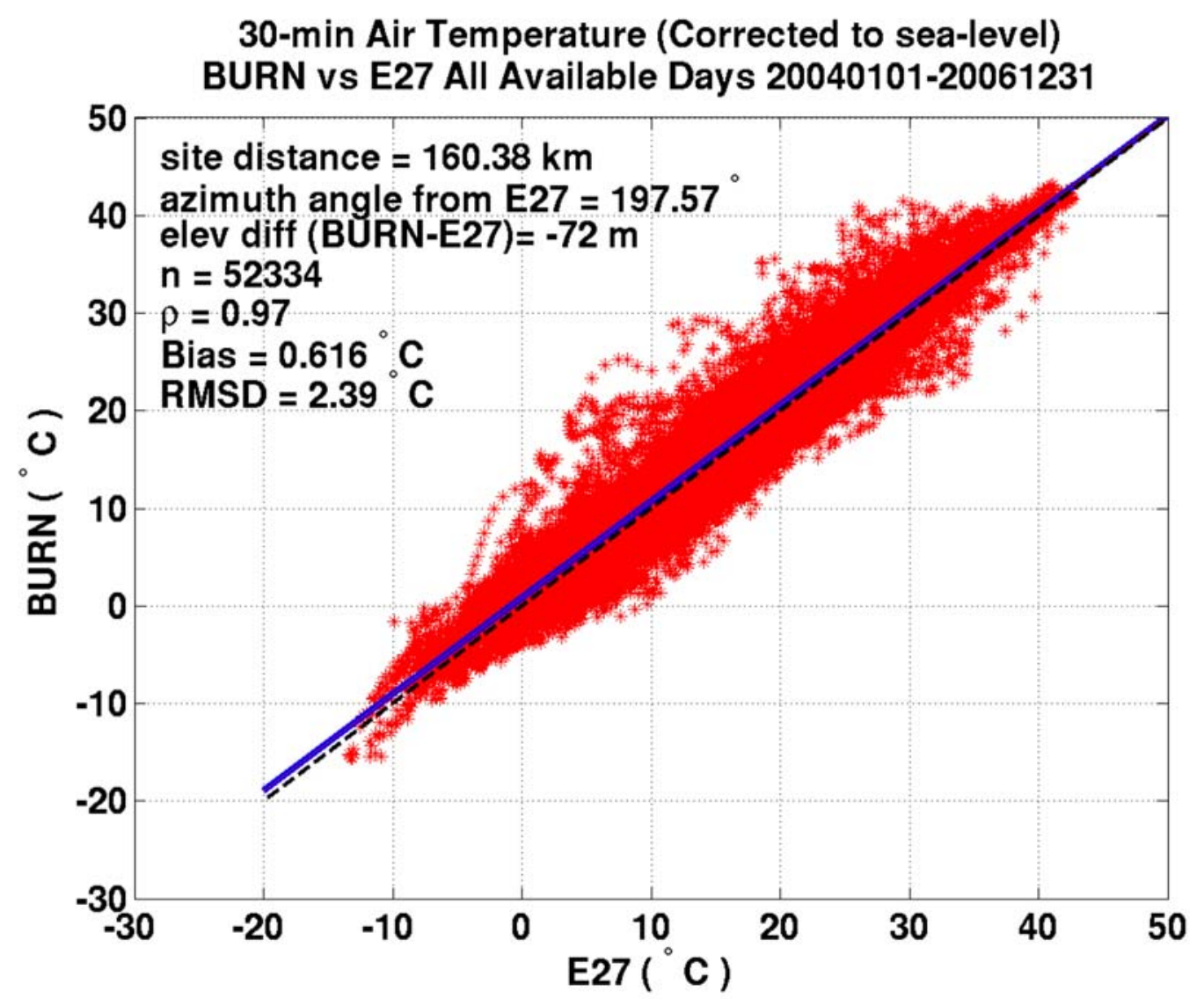

Figure 6: Scatter plot for the temperature comparison between the BURN OKM station and the E27 ARM SMOS station. Finger-like projections are evident near the $(x, y)$ coordinates $\left(-2^{\circ} \mathrm{C}, 5^{\circ} \mathrm{C}\right)$ and $\left(8^{\circ} \mathrm{C}, 25^{\circ} \mathrm{C}\right)$.

Finally, all $\rho$ and RMSD values from each domain were plotted together against the distances between station pairs to allow overall spatial patterns to be identified. These spatial comparisons were performed only with regard to distance between observation stations; no consideration was given to the directional component. A qualitative analysis of these plots revealed a mostly linear relationship between both $\rho$ and RMSD values and the distance between station pairs. As such, a linear LS model was fitted to the data in these plots to quantify the relationships of $\rho$ and RMSD with distance (Figures 7-10). The secondary sparse OK domains outlined in Table 1 were introduced to plot panel (a) of Figures 7-10 for illustrative purposes. In addition to the plots, the slopes and intercepts from each domain were compiled (Tables 3 and 4). Given the differences in sample size, the slopes and intercepts were similar for the sparse KS domain and the dense OK domains for both temperature and relative humidity. The secondary sparse domains demonstrated varied results. The slopes and intercepts for the secondary sparse northern OK domain centered on the E15 extended facility compared favorably with those for the sparse KS domain, while values for the secondary sparse central OK domain centered on the E27 extended facility appeared to differ more. Differences in the secondary sparse central OK domain were most notable for their RMSD values. 
(a)
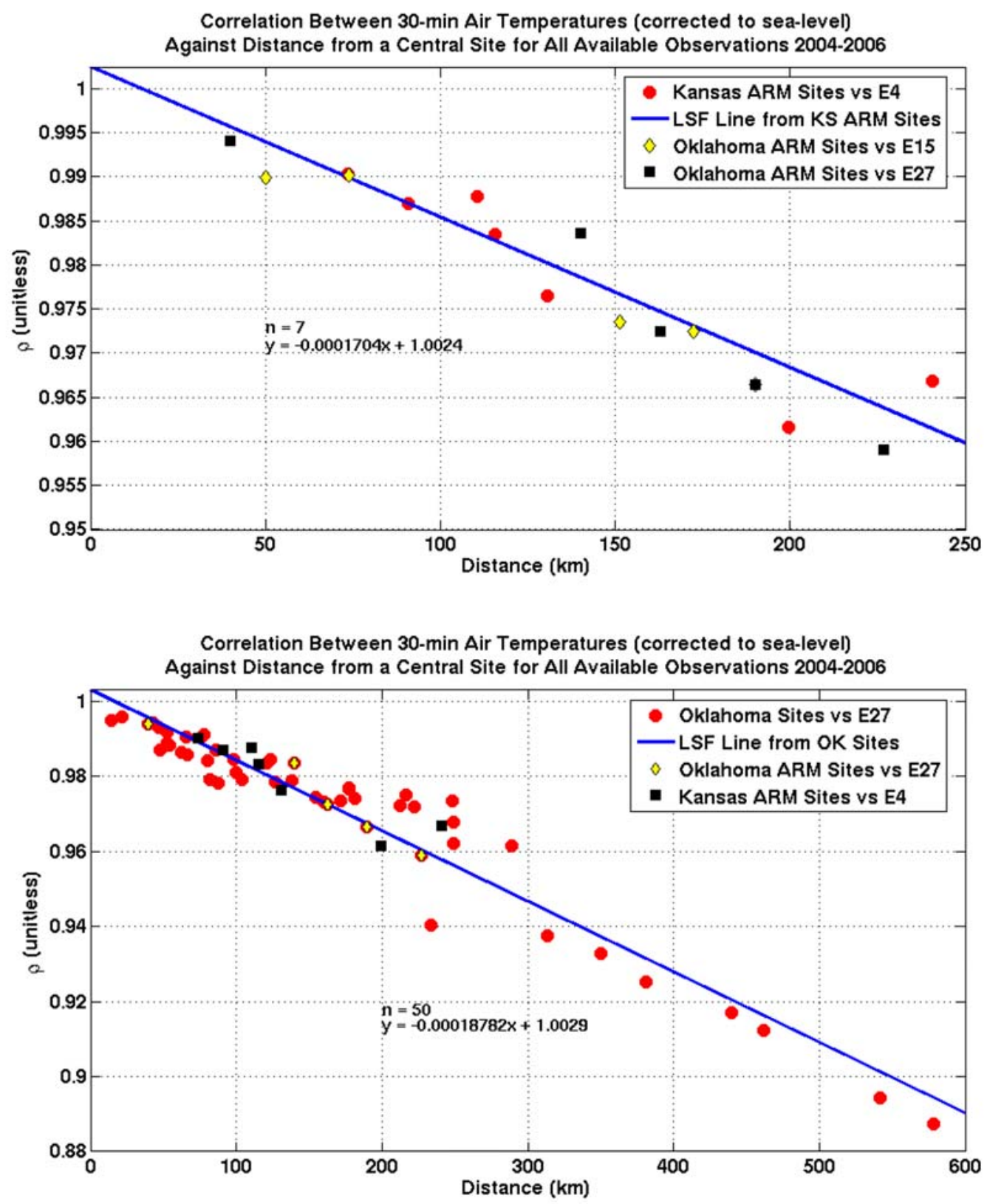

(b)

Figure 7: Scatter plots of $\rho$ for temperature versus distance for (a) ARM SMOS stations in the sparse $\mathrm{KS}$ domain and (b) OKM and ARM SMOS stations in the dense central OK domain. Note the different scales in the two plots. 
(a)

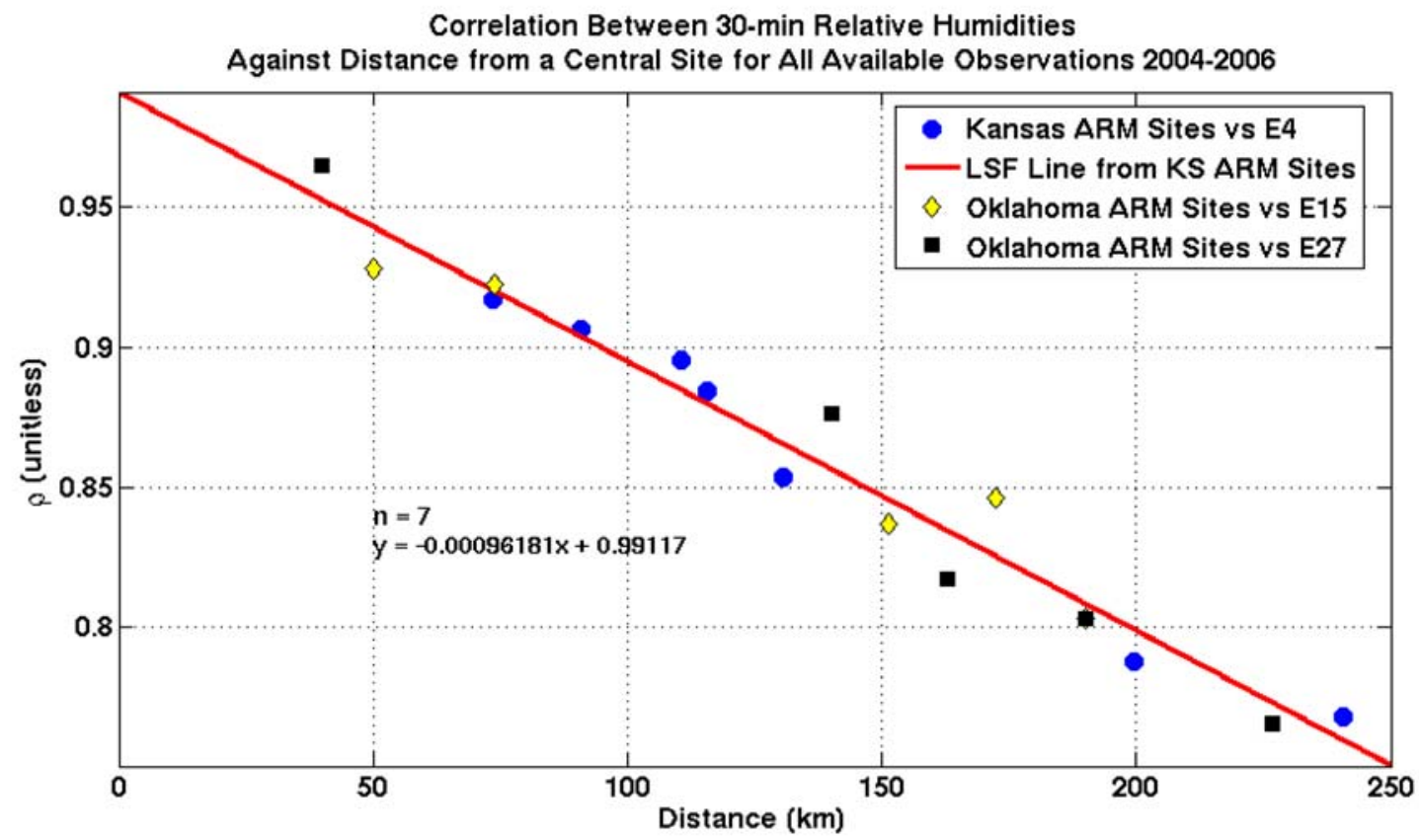

(b)

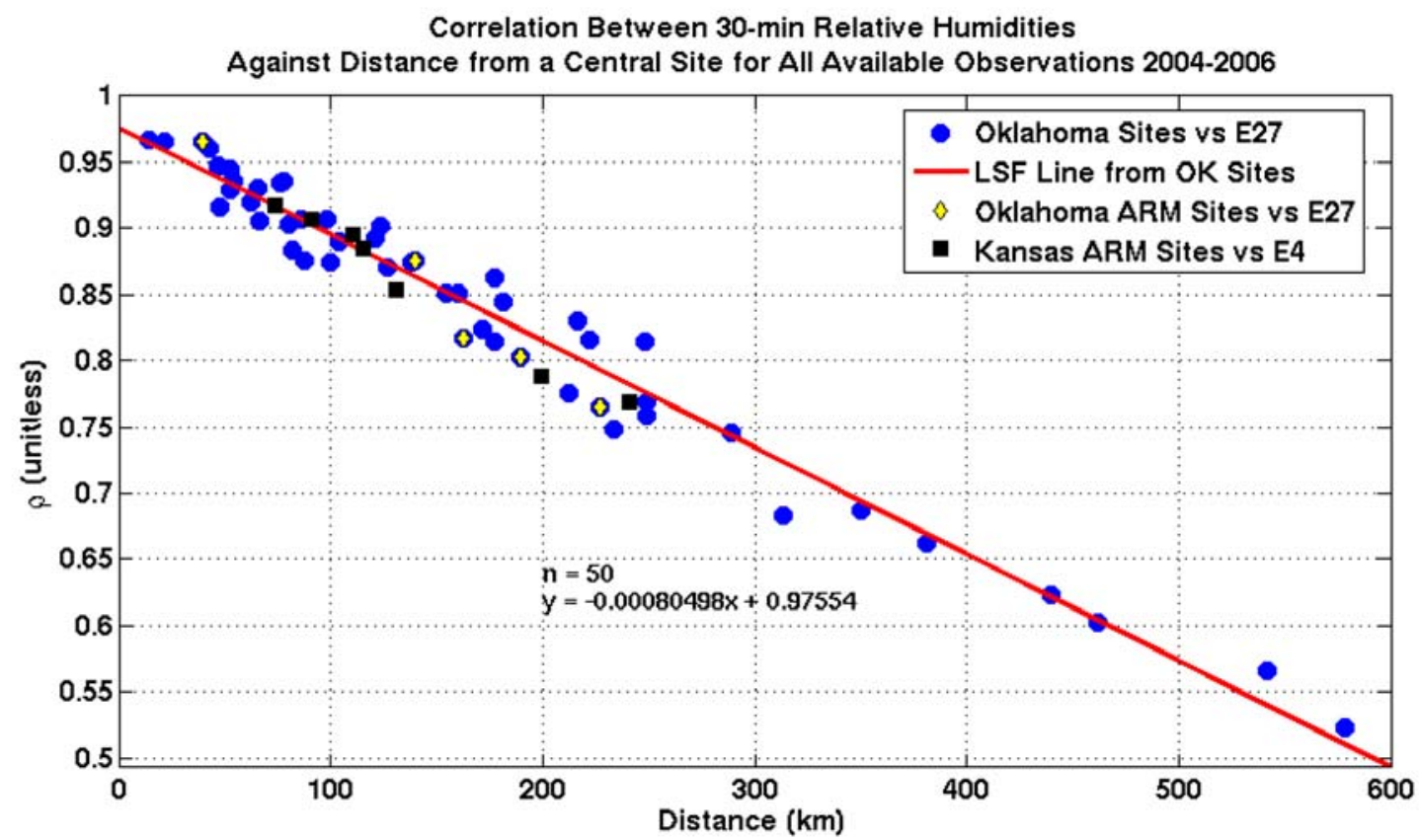

Figure 8: Scatter plots of $\rho$ for relative humidity versus distance for (a) ARM SMOS stations in the sparse KS domain and (b) OKM and ARM SMOS stations in the dense central OK domain. Note the different scales in the two plots. 
(a)

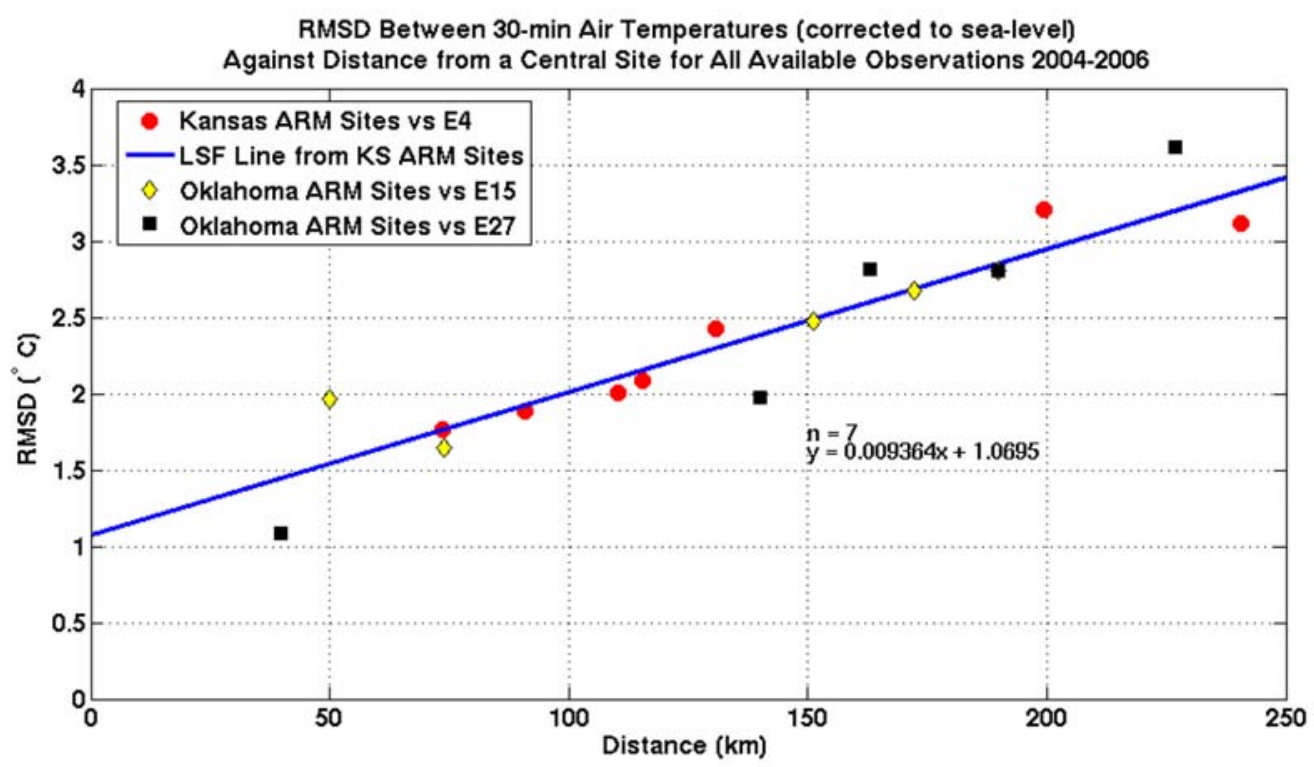

(b)

RMSD Between 30-min Air Temperatures (corrected to sea-level) Against Distance from a Central Site for All Available Observations 2004-2006

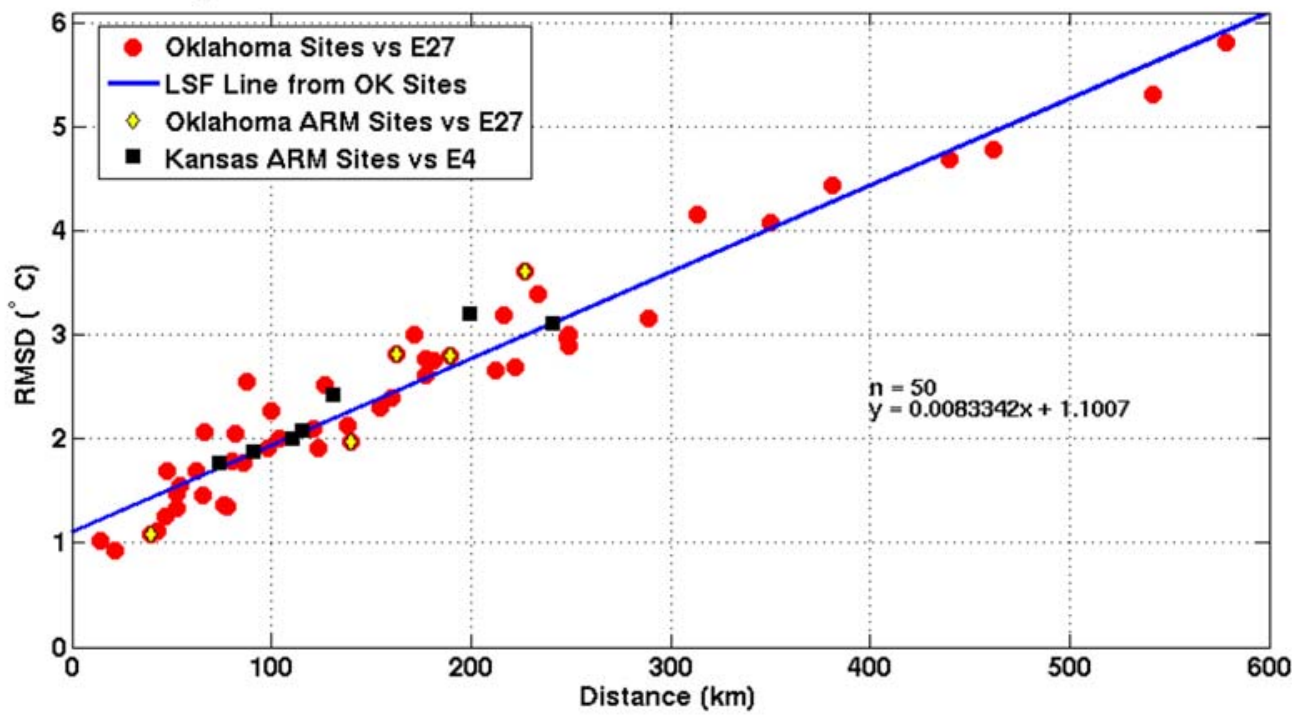

Figure 9: Scatter plots of RMSD for temperatures versus distance for (a) ARM SMOS stations in the sparse KS domain and (b) OKM and ARM SMOS stations in the dense central OK domain. Note the different scales in the two plots. 
(a)

RMSD Between 30-min Relative Humidities Against Distance from a Central Site for All Available Observations 2004-2006

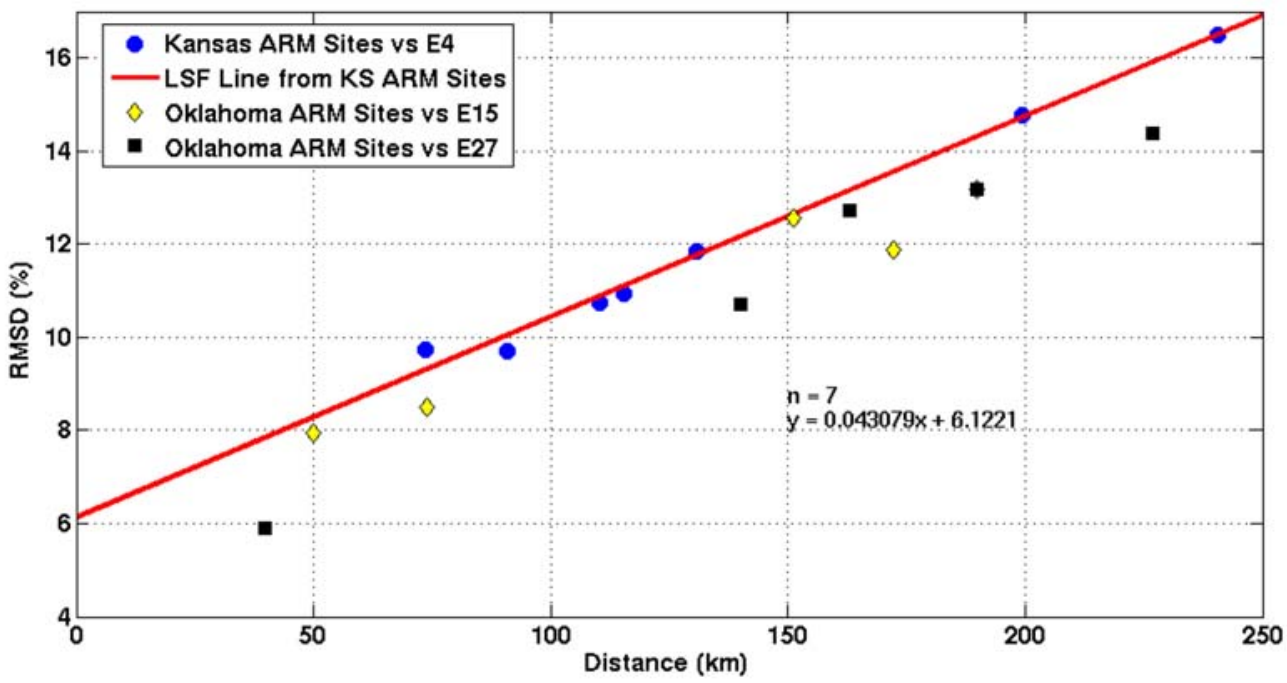

(b)

RMSD Between 30-min Relative Humidities

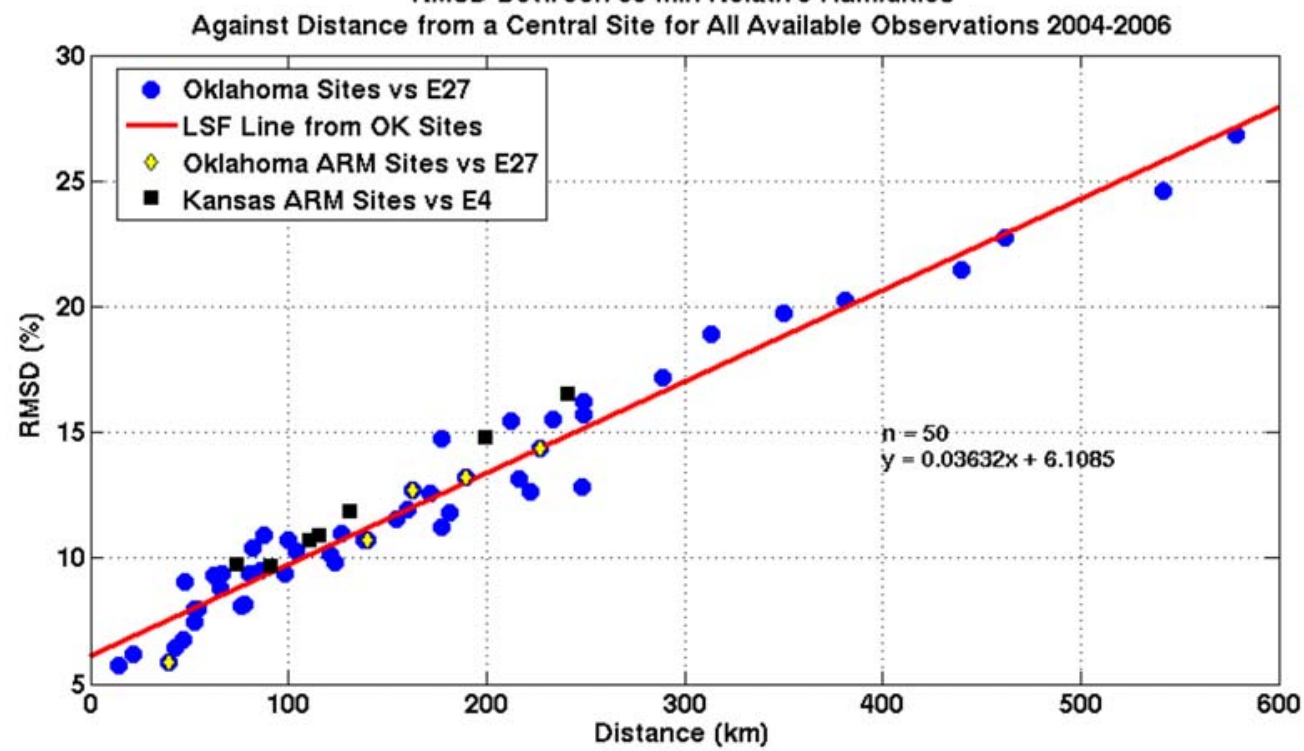

Figure 10: Scatter plots of RMSD for relative humidity versus distance for (a) ARM SMOS stations in the sparse KS domain and (b) OKM and ARM SMOS stations in the dense central OK domain. Note the different scales in the two plots. 
Table 3: Calculated slopes and intercepts of LS fit lines from distance analysis of $\rho$ in each domain.

\begin{tabular}{lccccc}
\hline & \multicolumn{5}{c}{ Domain $^{\mathrm{a}}$} \\
\cline { 2 - 6 } & $\begin{array}{c}\text { E4 vs. ARM } \\
\text { Calculated Quantity }\end{array}$ & $\begin{array}{c}\text { E15 vs. ARM } \\
(\mathrm{n}=7)\end{array}$ & $\begin{array}{c}\text { E27 vs. ARM } \\
(\mathrm{n}=5)\end{array}$ & $\begin{array}{c}\text { ARM/OKM } \\
(\mathrm{n}=50)\end{array}$ & $\begin{array}{c}\text { E27 vs. } \\
\text { ARM/OKM } \\
(\mathrm{n}=50)\end{array}$ \\
\hline Slope, $\mathrm{RH}\left(\mathrm{km}^{-1}\right)$ & $-9.6181 \times 10^{-4}$ & $-8.696 \times 10^{-4}$ & $-1.0895 \times 10^{-3}$ & $-8.2688 \times 10^{-4}$ & $-8.0498 \times 10^{-4}$ \\
Intercept, $\mathrm{RH}$ & 0.99117 & 0.97861 & 1.0111 & 0.978 & 0.97554 \\
Slope, temp $\left(\mathrm{km}^{-1}\right)$ & $-1.704 \times 10^{-4}$ & $-1.727 \times 10^{-4}$ & $-1.9053 \times 10^{-4}$ & $-2.0611 \times 10^{-4}$ & $-1.8782 \times 10^{-4}$ \\
Intercept, temp & 1.0024 & 1.0005 & 1.0041 & 1.0052 & 1.0029 \\
\hline a Comparison station locations: E4, sparse KS domain; E15, dense northern OK domain; E27, dense \\
$\begin{array}{l}\text { central OK domain. } \\
\text { b RH, relative humidity; temp, temperature; intercepts are unitless. }\end{array}$
\end{tabular}

Table 4: Calculated slopes and intercepts of LS fit lines from distance analysis of RMSD in each domain.

\begin{tabular}{|c|c|c|c|c|c|}
\hline \multirow[b]{2}{*}{ Calculated Quantityb } & \multicolumn{5}{|c|}{ Domaina } \\
\hline & $\begin{array}{l}\text { E4 vs. ARM } \\
\quad(n=7)\end{array}$ & $\begin{array}{l}\text { E15 vs. ARM } \\
\quad(n=5)\end{array}$ & $\begin{array}{c}\text { E27 vs. ARM } \\
(n=5)\end{array}$ & $\begin{array}{l}\text { E15 vs. } \\
\text { ARM-OKM } \\
(n=50)\end{array}$ & $\begin{array}{l}\text { E27 vs. } \\
\text { ARM-OKM } \\
(n=50)\end{array}$ \\
\hline Slope, $\mathrm{RH}\left(\% \mathrm{~km}^{-1}\right)$ & $4.3077 \times 10^{-2}$ & $3.814 \times 10^{-2}$ & $4.6822 \times 10^{-2}$ & $3.4332 \times 10^{-2}$ & $3.632 \times 10^{-2}$ \\
\hline Intercept, RH (\%) & 6.1223 & 5.9487 & 4.2706 & 6.6837 & 6.1085 \\
\hline $\begin{array}{l}\text { Slope, temp } \\
\left({ }^{\circ} \mathrm{C} \mathrm{km}^{-1}\right)\end{array}$ & $9.3635 \times 10^{-3}$ & $7.4297 \times 10^{-3}$ & $1.3239 \times 10^{-2}$ & $8.9541 \times 10^{-3}$ & $8.3342 \times 10^{-3}$ \\
\hline Intercept, temp $\left({ }^{\circ} \mathrm{C}\right)$ & 1.0695 & 1.3661 & 0.44839 & 1.1232 & 1.1007 \\
\hline
\end{tabular}

\section{Preliminary Conclusions}

The information gained by plotting $\rho$ and RMSD versus distance (Figures 7-10) provided insight into the spatial variability of temperature and relative humidity across KS and OK. Generally, the slope and intercept values calculated from the LS fit equations were comparable between the domains over the time period 2004-2006. Despite this result, the sample sizes for the distance analyses of the sparse domains were small enough so that subtle changes in values of $\rho$ or RMSD could greatly impact the calculated slopes and intercepts.

Temperature and relative humidity were positively correlated for all station pairs. At a given distance, $\rho$ values were larger for temperature than for relative humidity, while RMSD values were smaller for temperature. Brotzge and Richardson (2003) noted a similar result in their comparison of OKM temperature and relative humidity values, averaged daily. Temperature tended to de-correlate more slowly than relative humidity as inter-station distance increased, and RMSD values calculated for temperature tended to increase more slowly than did values calculated for relative humidity as distance increased. 
Qualitatively, the relative humidity results for the dense OK domains indicated that a station distance $\leq \sim 100 \mathrm{~km}$ would achieve values of $\rho \geq \sim 0.88$ and RMSD $\leq \sim 10 \%$. The inter-station relationship for temperature was much stronger, as a station spacing of $\sim 100 \mathrm{~km}$ over OK resulted in values of $\rho \geq \sim 0.98$ and $\mathrm{RMSD} \leq \sim 2-2.5^{\circ} \mathrm{C}$. These preliminary results suggest that the greater density of the OKM network is more helpful in resolving spatial differences in relative humidity than differences in temperature. Temperature is less spatially heterogeneous, and therefore sufficient spatial variability may be captured even if stations are placed at a greater distance than the network average of $\sim 30 \mathrm{~km}$ between an OKM station and the closest neighboring station. However, the calculations for the dense OK domains provide more confidence because of their greater sample size and spatial coverage.

In summary, we conclude that

- Sparse networks are limited to a threshold of accuracy for the spatial representation of temperature and relative humidity.

- The ideal station spacing in a network depends on the meteorological variable being examined.

Extending this study to time periods when other climatic conditions prevailed could have affected the results. However, the mostly linear relationship between both $\rho$ and RMSD versus distance was promising, given the anomalous climatic conditions during the extended drought across much of OK in 2005-2006. Performing this analysis on a seasonal time scale or shorter would aid in understanding whether correlations between stations are different at separate times of the year, as well as to what extent the signal from specific weather events might have been masked by longer-term mean values. Finally, it would be useful to categorize the results by direction and distance rather than distance alone, because a study by Brotzge and Richardson (2003) demonstrated that spatial correlations of temperature and relative humidity tended to be strongest from southeast to northwest across OK, along prevailing flow patterns near the surface.

\section{References}

Brotzge, JA, and SJ Richardson. 2003. "Spatial and temporal correlation among Oklahoma Mesonet and OASIS surface-layer measurements.” Journal of Applied Meteorology 42:5-19.

McManus, GD, editor. 2004. Oklahoma Climate Fall 2004, Oklahoma Climatological Survey. University of Oklahoma, Norman, Oklahoma (linked at http://climate.mesonet.org/ seasonal_summary.html).

McManus, GD, editor. 2006. Oklahoma Climate Summer 2006, Oklahoma Climatological Survey. University of Oklahoma, Norman, Oklahoma (linked at http://climate.mesonet.org/ seasonal_summary.html).

McPherson, RA, C Fiebrich, KC Crawford, RL Elliott, JR Kilby, DL Grimsley, JE Martinez, JB Basara, BG Illston, DA Morris, KA Kloesel, SJ Stadler, AD Melvin, AJ Sutherland, and H Shrivastava. 2007. "Statewide monitoring of the mesoscale environment: A technical update on the Oklahoma Mesonet." Journal of Atmospheric and Oceanic Technology 24:301-321. 
Peppler, RA, KE Kehoe, KL Sonntag, CP Bahrmann, SJ Richardson, SW Christensen, RA McCord, KJ Doty, R Wagener, RC Eagan, JC Liljegren, BW Orr, DL Sisterson, TD Halter, NN Keck, CN Long, MC Macduff, JH Mather, RC Perez, JW Voyles, MD Ivey, ST Moore, KL Nitschke, BD Perkins, and DD

Turner. 2008. Quality assurance of ARM Program Climate Research Facility data. U.S. Department of Energy DOE/SC-ARM/TR-082. 